Check for updates

Cite this: RSC Adv., 2018, 8, 11886

Received 17th December 2017

Accepted 21st March 2018

DOI: $10.1039 / c 7 r a 13402 a$

rsc.li/rsc-advances

\title{
Efficient separation of rare earths recovered by a supported ionic liquid from bauxite residue leachate $\dagger$
}

\begin{abstract}
Dženita Avdibegović, (D) Mercedes Regadío (iD) and Koen Binnemans (D)*
Bauxite residue (BR) contains substantial concentrations of rare-earth elements (REEs), but their recovery is a challenge. Acidic BR leachates typically comprise much higher concentrations of base elements $\left(\mathrm{g} \mathrm{L}^{-1}\right)$ than those of the REEs (ppm). Thus, adsorbents that are highly selective for the REEs over the base elements are required for the separation. The novel supported ionic liquid phase (SILP) betainium sulfonyl(trifluoromethanesulfonylimide) poly(styrene-co-divinylbenzene) [Hbet-STFSI-PS-DVB] was evaluated for the uptake of REEs ( $\mathrm{Sc}, \mathrm{Y}, \mathrm{Nd}$, Dy) in the presence of base elements ( $\mathrm{Ca}, \mathrm{Al}, \mathrm{Fe}$ ) from $\mathrm{BR}$ leachates. Breakthrough curves from acidic nitrate and sulfate media were investigated, as both $\mathrm{HNO}_{3}$ and $\mathrm{H}_{2} \mathrm{SO}_{4}$ are commonly used for leaching of BR. The SILP exhibited a superior affinity for REEs in both media, except in the case of Sc(III) from the sulfate feed. The recovery rates of the trace amounts of REES from the real nitrate feed were remarkably high (71.7-100\%) via a simple chromatography separation, without requiring complexing agents or a pretreatment for the removal of interfering elements. The REEs were purified from the base elements and separated into three sub-groups (scandium, light REEs and heavy REEs) by an optimized elution profile with $\mathrm{H}_{3} \mathrm{PO}_{4}$ and $\mathrm{HNO}_{3}$ in a single chromatographic separation step.
\end{abstract}

\section{Introduction}

The rare-earth elements (REEs) are nowadays considered as strategic elements because of their importance for modern technology and clean-tech applications., ${ }^{1,2}$ REE deposits in China and the United States constitute the largest percentage of REE economic resources worldwide. ${ }^{1}$ In fact, China is the major supplier of REEs to the European Union. ${ }^{3}$ European Union complete dependency on the REEs import classifies REEs as critical materials and enforces the search for innovative recycling schemes.

Bauxite residue (BR) or red mud is a by-product generated after alkali leaching of bauxite for alumina production in the Bayer process. ${ }^{4-8}$ The variation in BR composition is extremely wide but generally $\mathrm{BR}$ is rich in $\mathrm{Fe}_{2} \mathrm{O}_{3}$ (5-60 wt\%), $\mathrm{Al}_{2} \mathrm{O}_{3}$ (5$30 \mathrm{wt} \%), \mathrm{TiO}_{2}(0.3-15 \mathrm{wt} \%), \mathrm{CaO}(2-14 \mathrm{wt} \%), \mathrm{SiO}_{2}(3-50 \mathrm{wt} \%)$ and $\mathrm{Na}_{2} \mathrm{O}(1-10 \mathrm{wt} \%)^{9,}{ }^{9,10}$ Apart from the base elements, BR comprises trace amounts of REEs. In the Bayer process REEs pass almost entirely from bauxite into the BR. ${ }^{11}$ For instance, Sc and $\mathrm{Y}$ concentrations in a typical $\mathrm{BR}$ are $121 \mathrm{~g}$ tonne $\mathrm{e}^{-1}$ and

KU Leuven, Department of Chemistry, Celestijnenlaan 200F, P. O. Box 2404, B-3001 Leuven, Belgium. E-mail: Koen.Binnemans@kuleuven.be; Tel: +32 16327446

$\dagger$ Electronic supplementary information (ESI) available: Equation of space velocity. Tables with separation factors. Tables with quantities and purities of the REE in different collected fractions under different conditions. See DOI: 10.1039/c7ra13402a
$75.7 \mathrm{~g}$ tonne ${ }^{-1}$, respectively. ${ }^{12}$ These values exceed the reported concentrations of Sc $\left(48.9 \mathrm{~g}\right.$ tonne $\left.^{-1}\right)$ and $\mathrm{Y}\left(18.8 \mathrm{~g}\right.$ tonne $\left.^{-1}\right)$ in the ion-adsorption REE ore from the Yunnan Province of China. ${ }^{13}$ Considering its high annual production (140 million tonnes), BR represents an interesting and valuable by-product for REEs recovery. Leaching of BR with mineral acids is a frequent process prior to REEs recovery by solvent extraction or ion-exchange. ${ }^{12,14-20}$ The leaching process depends on the type of BR since its mineralogical composition is complex and comprises some minerals which are present in the bauxite and others that are produced during the Bayer process. ${ }^{9,18,21}$ The leachates typically have high concentrations of base elements that are normally present in the BR and significantly lower concentrations of REEs. ${ }^{10,12,18,22}$ This diversity of compounds and concentration range of the REEs in the BR leachates makes the REE recovery and separation a challenging task.

Previously the synthesis of the novel supported ionic liquid phase (SILP) betainium sulfonyl(trifluoromethanesulfonylimide) poly(styrene-co-divinylbenzene) [Hbet-STFSI-PS-DVB] by covalent bonding of ion pairs onto the PS-DVB matrix was described (Fig. 1). ${ }^{23}$ The SILP was specially designed for the efficient Sc(III) uptake from acidic solutions. The SILP stands out for its fast adsorption kinetics and higher $\mathrm{Sc}(\mathrm{III})$ uptake in the presence of equimolar concentrations of $\mathrm{Ca}(\mathrm{II}), \mathrm{Al}(\mathrm{III})$ and $\mathrm{Fe}(\mathrm{III})$. In the present paper, the possibility of REEs recovery and separation from BR leachates by the SILP and column chromatography operation was further explored. 


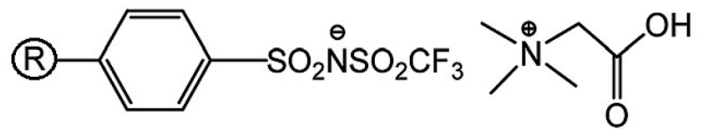

Fig. 1 Structure of the SILP betainium sulfonyl(trifluoromethanesulfonylimide) poly(styrene-co-divinylbenzene) [HbetSTFSI-PS-DVB].

\section{Experimental}

\section{Chemicals}

$\mathrm{HNO}_{3}(65 \%), \mathrm{Al}_{2}\left(\mathrm{SO}_{4}\right)_{3} \cdot 18 \mathrm{H}_{2} \mathrm{O}(100-110 \%)$, standard solutions of scandium $\left[(1000 \pm 2) \mu \mathrm{g} \mathrm{mL} \mathrm{m}^{-1}\right]$, yttrium $[(1000 \pm 10) \mu \mathrm{g}$ $\left.\mathrm{mL}^{-1}\right]$, neodymium $\left[(1000 \pm 2) \mu \mathrm{g} \mathrm{mL}^{-1}\right]$, dysprosium $[(1000 \pm$ 2) $\left.\mu \mathrm{g} \mathrm{mL}{ }^{-1}\right]$, lanthanum $\left[(1000 \pm 10) \mu \mathrm{g} \mathrm{mL}{ }^{-1}\right]$, gallium $[(1000$ $\left.\pm 10) \mu \mathrm{g} \mathrm{mL}{ }^{-1}\right]$, aluminum $\left[(1000 \pm 10) \mu \mathrm{g} \mathrm{mL} \mathrm{mL}^{-1}\right]$, iron $[(1000$ $\left.\pm 10) \mu \mathrm{g} \mathrm{mL} \mathrm{m}^{-1}\right]$, titanium $\left[(1000 \pm 10) \mu \mathrm{g} \mathrm{mL} \mathrm{L}^{-1}\right]$, silicium $\left[(1000 \pm 10) \mu \mathrm{g} \mathrm{mL}{ }^{-1}\right]$ and calcium $\left[(1000 \pm 10) \mu \mathrm{g} \mathrm{mL}^{-1}\right]$ were purchased from Chem-Lab NV (Zedelgem, Belgium). $\mathrm{Sc}\left(\mathrm{NO}_{3}\right)_{3} \cdot 5 \mathrm{H}_{2} \mathrm{O}$ (99.9\%), $\mathrm{Nd}\left(\mathrm{NO}_{3}\right) \cdot 6 \mathrm{H}_{2} \mathrm{O}$ (99.9\%), Dy $\left(\mathrm{NO}_{3}\right) \cdot$ $6 \mathrm{H}_{2} \mathrm{O}(99.9 \%)$ and $\mathrm{YCl}_{3} \cdot 6 \mathrm{H}_{2} \mathrm{O}(99.9 \%)$ were purchased from Strem Chemicals (Newburyport, USA). $\mathrm{CaSO}_{4} \cdot 2 \mathrm{H}_{2} \mathrm{O}, \mathrm{FeNO}_{3}$ $\cdot 9 \mathrm{H}_{2} \mathrm{O}(>99 \%), \mathrm{Fe}_{2}\left(\mathrm{SO}_{4}\right)_{3} \cdot x \mathrm{H}_{2} \mathrm{O}$ (p.a.) were purchased from Vel (Leuven. Belgium). $\mathrm{Nd}_{2}\left(\mathrm{SO}_{4}\right)_{3} \cdot x \mathrm{H}_{2} \mathrm{O}(99.9 \%)$ and $\mathrm{CaCO}_{3}$ (99.999\%) were purchased from Alfa Aesar (Karlsruhe, Germany). DyCl $3 \cdot 6 \mathrm{H}_{2} \mathrm{O}(99.9 \%)$ was purchased from abcr (Karlsruhe, Germany). $\mathrm{Al}\left(\mathrm{NO}_{3}\right)_{3} \cdot 9 \mathrm{H}_{2} \mathrm{O}(>98.5 \%)$ was purchased from Sigma-Aldrich (Steinheim, Germany). Phosphoric acid (85\%) was purchased from Ashland Chemicals (Columbus, USA). Betaine hydrochloride (99\%), triethylamine (99\%), and sulfuric acid (96\%) were purchased from Acros Organics (Geel, Belgium). Sodium hydroxide (97\%) was purchased from VWR (Leuven, Belgium). Polystyrene-divinylbenzene (PS-DVB) sulfonyl chloride resin (0.91 $\mathrm{mmol} \mathrm{g}^{-1}, 200-400$ mesh) was purchased from RappPolymere (Tübingen, Germany). Trifluoromethanesulfonamide (98\%) was purchased from J\&K Scientific GmbH (Pforzheim, Germany). Dichloromethane (DCM) (p.a.) and acetone (p.a.) were purchased from Fisher Chemical (Loughborough, UK). $\mathrm{Sc}_{2} \mathrm{O}_{3}$ (99.99\%) was kindly provided by Solvay (La Rochelle, France). Hydrated $\mathrm{Sc}_{2}\left(\mathrm{SO}_{4}\right)_{3}$ was prepared from $\mathrm{Sc}_{2} \mathrm{O}_{3}$ as previously described in the literature. ${ }^{24}$ Hydrated $\mathrm{Y}_{2}\left(\mathrm{SO}_{4}\right)_{3}$ and $\mathrm{Dy}_{2}\left(\mathrm{SO}_{4}\right)_{3}$ were prepared in the same manner from $\mathrm{YCl}_{3}$ and $\mathrm{DyCl}_{3}$, respectively. $\mathrm{Ca}\left(\mathrm{NO}_{3}\right)_{2}$ was prepared from $\mathrm{CaCO}_{3}$ by dissolution in $\mathrm{HNO}_{3}$. The concentrations of the stock solutions were measured by TXRF or ICPOES (see next section).

\section{Equipment}

Batch adsorption experiments were performed using a VWR International water bath shaker (Type 462-0355). A fraction collector CF-2 (Spectrum Laboratories, Inc.) equipped with drop sensor and IPC 8-channel peristaltic pump (ISMATEC) was used for sampling during the chromatography studies. An inductively coupled plasma - optical emission spectrometer (ICPOES) (Perkin Elmer OPTIMA 8300) was used to measure concentrations of elements in the solutions. The calibration solutions and all samples were prepared by dilution with $2 \mathrm{wt} \%$ $\mathrm{HNO}_{3}$. Lanthanum (5 ppm) was used as an internal standard. The following spectral lines were used for quantification (wavelengths in nm): Ca 317.933, Fe 238.204, Sc 361.383, Y 371.029, Al 308.215, Nd 401.225, Dy 394.468, Si 251.611, Ti 334.940, La 408.672.

\section{Batch adsorption tests}

Typically, $0.05 \mathrm{~g}$ of the SILP (32 wt \% of moisture) was placed in a $20 \mathrm{~mL}$ glass vial and $10 \mathrm{~mL}$ of synthetic equimolar feed solution of Sc(III), Y(III), Nd(III) and Dy(III) with total concentration of $1.2 \mathrm{mM}$ and with previously adjusted $\mathrm{pH}$ was added. The samples were shaken for 90 minutes at room temperature and $300 \mathrm{rpm}$. Further, the samples were filtered through a syringe filter with $0.20 \mu \mathrm{m}$ pore size. The filtrate was then diluted to an appropriate concentration for ICP-OES analysis, typically 10 times, with $2 \mathrm{wt} \% \mathrm{HNO}_{3}$ prior to the measurement. The amount of metal ions adsorbed onto the SILP was calculated from eqn (1) and the separation between elements by eqn (2) and (3).

$$
q=\frac{\left(c_{\mathrm{ini}}-c_{\mathrm{eq}}\right) V}{m_{\mathrm{ads}}}
$$

The amount of adsorbed metal ions at equilibrium ( $m m o l ~ \mathrm{~g}^{-1}$ of dry adsorbent) is given by $q$, the initial metal ion concentration in the solution $\left(\mathrm{mmol} \mathrm{L}^{-1}\right)$ is $c_{\mathrm{ini}}$, the equilibrium concentration of metal ions in the solution $\left(\mathrm{mmol} \mathrm{L}^{-1}\right)$ is $c_{\mathrm{eq}} \cdot V$ is the volume of the solution (L) and $m_{\text {ads }}$ is the mass of the dry adsorbent ( $\mathrm{g})$.

$$
K_{\mathrm{d}}=\frac{q}{c_{\mathrm{eq}}}
$$

The distribution coefficient $\left(K_{\mathrm{d}}\right)$ is the ratio of the adsorbed amount of metal divided by its concentration in solution at equilibrium $\left(\mathrm{L} \mathrm{g}^{-1}\right), q$ is the amount of adsorbed metal ion calculated from the eqn (1), and $c_{\text {eq }}$ is the equilibrium concentration.

$$
\alpha_{\mathrm{A} / \mathrm{B}}=\frac{K_{\mathrm{dA}}}{K_{\mathrm{dB}}} \quad \text { when } K_{\mathrm{dA}} \geq K_{\mathrm{dB}}
$$

$\alpha_{\mathrm{A} / \mathrm{B}}$ is the separation factor between two metals A and B.

\section{Column chromatography tests}

A gravity flow glass column (BIO-RAD) of $30 \mathrm{~cm}$ length and $0.7 \mathrm{~cm}$ diameter was used in chromatography separation experiments. The column was packed with the SILP (1.36 g of the SILP, dry mass) by a wet method to a bed volume (BV) of approximately $10.8 \mathrm{~mL}$. Unless otherwise stated, the SILP was preconditioned with $\mathrm{HNO}_{3}$ or $\mathrm{H}_{2} \mathrm{SO}_{4}$ solution $(\mathrm{pH}=1.5)$ prior to each experiment. For breakthrough curve experiments, a $1.1 \mathrm{mmol} \mathrm{L}^{-1}$ equimolar solution of Sc, Y, Nd, Dy, Fe, Al, Ca in nitrate or sulfate media (initial $\mathrm{pH}, \mathrm{pH}_{\mathrm{ini}}=1.5$ ) was pumped through the column until complete saturation of the SILP was reached. For optimization of the separation process, $10.0 \mathrm{~mL}$ of an equimolar solution was loaded onto the SILP. The $\mathrm{pH}_{\mathrm{ini}}$ was 
set to 1.5 to mimic the adsorption from the acidic BR leachates. To remove possible impurities in the sample tubes, $\mathrm{HNO}_{3}$ or $\mathrm{H}_{2} \mathrm{SO}_{4}$ was loaded prior to the eluting agent for the subsequent separation process. Typically, $5 \mathrm{~mL}$ of the corresponding acid with $\mathrm{pH}$ equal to the $\mathrm{pH}_{\mathrm{ini}}$ of the sample was used. Prior to and after loading of the real $\mathrm{BR}$ leachate, $15.0 \mathrm{~mL}$ of $\mathrm{HNO}_{3}$ $(\mathrm{pH}=1.2)$ was used for the preconditioning and washing step. For each experiment, $5.0 \mathrm{~mL}$ fractions were collected and analyzed by ICP-OES. All column chromatography experiments were conducted at room temperature. Unless otherwise stated, the flow rate was set at $0.5 \mathrm{~mL} \mathrm{~min}^{-1}$. This value corresponds to a space velocity (SV) of $2.7 \mathrm{~h}^{-1}$ [ratio of the volumetric flow rate $\left(\mathrm{mL} \mathrm{h}^{-1}\right)$ to the $\mathrm{BV}(\mathrm{mL})$, eqn $\left.\mathrm{S} 1 \dagger\right] .^{25}$

\section{Leaching of bauxite residue}

A sample of BR was kindly provided by Aluminium of Greece (Agios Nikolaos, Greece). ${ }^{12}$ The characterization of this Greek BR has been previously reported in several studies. ${ }^{12,15,26}$ The leaching of $\mathrm{BR}$ was performed as described in previous studies. ${ }^{12}$ About $4 \mathrm{~g}$ of BR was air-dried for 20 hours at $105{ }^{\circ} \mathrm{C}$. An amount of $20.0 \mathrm{~mL}$ of $0.7 \mathrm{~N} \mathrm{HNO}_{3}$ was added to $2.00 \mathrm{~g}$ of BR. The mixture was shaken for 6 hours on a Thermo Fisher shaker at $250 \mathrm{rpm}$ at room temperature. The samples were filtered through a $0.20 \mu \mathrm{m}$ pore size syringe filter and $2.0 \mathrm{~mL}$ of the freshly prepared leachate was used for a chromatography separation experiment.

\section{Results and discussion}

The effect of the solution $\mathrm{pH}$ on the REEs adsorption was studied in batch adsorption tests of the SILP with nitrate and sulfate synthetic solution, as the $\mathrm{pH}$ is one of the predominant parameters that can affect the adsorption by the SILP. Moreover, for the study of REEs purification from the base elements, adsorption and elution tests of the SILP in a column setup were performed with synthetic nitrate and sulfate multi-element equimolar solutions. Finally, the performance of the SILP for REEs separation and purification was studied and verified with the real $\mathrm{HNO}_{3} \mathrm{BR}$ leachate.

\section{Adsorption of REEs by the SILP in batch experiments}

$\mathrm{HNO}_{3}$ and $\mathrm{H}_{2} \mathrm{SO}_{4}$ are commonly used for BR leaching. ${ }^{12,16,22}$ In different media, different REEs complexes form, which might affect the REEs uptake and selectivity. Therefore, the adsorption experiments were initially conducted batchwise from both nitrate and sulfate media. ${ }^{27}$ It was confirmed that the SILP can adsorb the REEs under acidic conditions from both media (Fig. 2). With the increase in the equilibrium $\mathrm{pH}$ value $\left(\mathrm{pH}_{\mathrm{eq}}\right.$ from 0.5 to 2.5), the amount of the REEs adsorbed by the SILP increased. The uptake of Sc(III) was less pronounced than that of other REEs at $\mathrm{pH}_{\mathrm{eq}}<2.5$. The small ionic radius of $\mathrm{Sc}$ (III) and therefore high charge density and hydration enthalpy might partially explain the lower uptake of Sc(III). ${ }^{27-29}$ In the presence of sulfate anions $\mathrm{Sc}(\mathrm{III})$ can form negatively charged sulfato complexes which cannot undergo cation exchange with the proton of the SILP. ${ }^{22,30}$ Therefore, in the sulfate media the
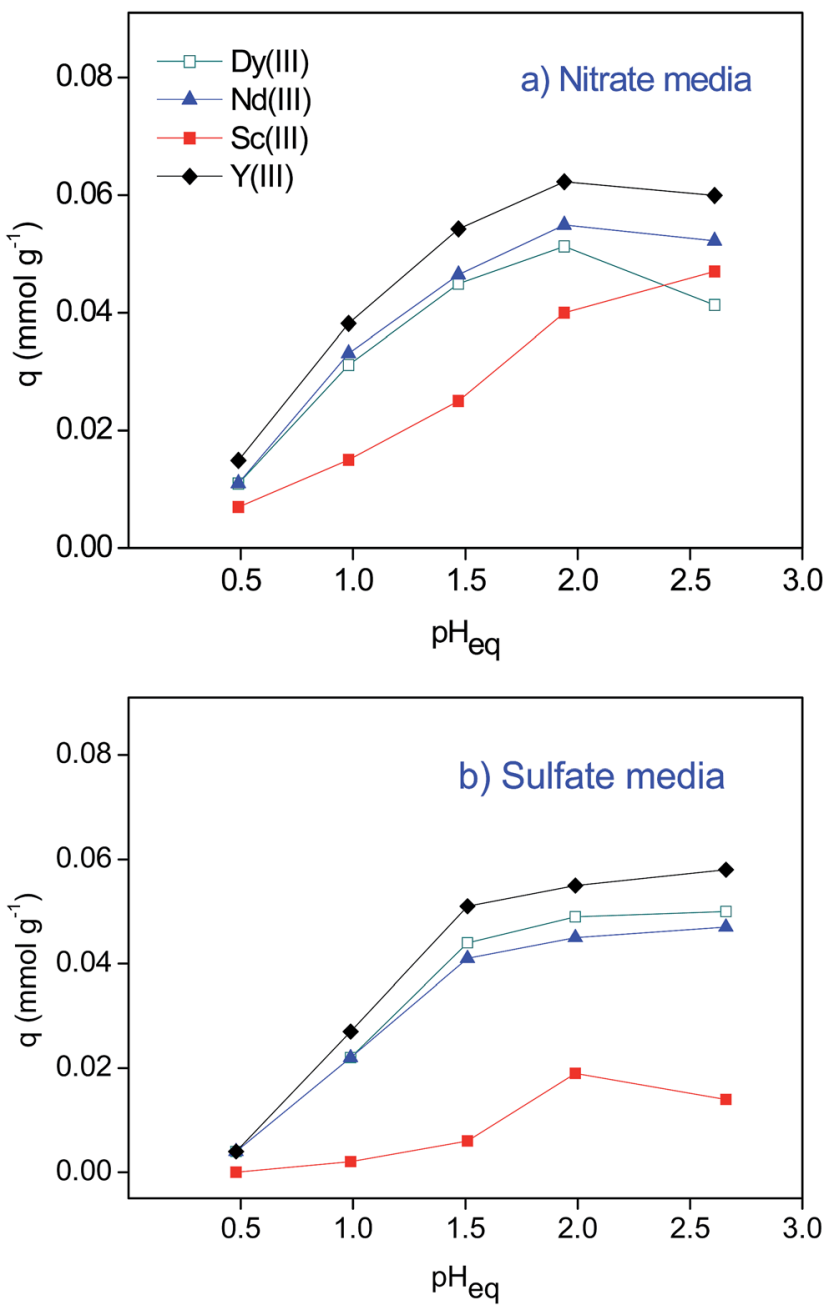

Fig. 2 Adsorption of REEs by the SILP from multi-element equimolar solution (total $c \approx 1.2 \mathrm{mM}$ ) as a function of the equilibrium $\mathrm{pH}$ from (a) nitrate and (b) sulfate media. The relative standard deviation (RSD) of triplicate measurement by ICP-OES was less than $3 \%$.

resulting $q$ was $<0.02 \mathrm{mmol} \mathrm{g}^{-1}$. As a result, the separation factors (eqn (2) and 3) between Sc(III) and other REEs were up to 4.2 (Table S1†). The other three investigated REEs, Dy(III), Nd(III) and $\mathrm{Y}(\mathrm{III})$, were adsorbed to a similar extent resulting in low separation factors (from 1.1 to 1.5 ) (Table $\mathrm{S} 2 \dagger$ ). Thus, to improve the separation of the REEs by the SILP, column chromatography needed to be considered (vide infra).

\section{Breakthrough curves by the SILP in a fixed bed column}

The preferential uptake and dynamic loading capacity of the SILP were estimated based on breakthrough curves with the assumption of a Langmuir isotherm (Fig. 3). The breakthrough point was set at $c / c_{0}=0.05$ and the exhaustive point at $c / c_{0}=1$. Generally a high preferential uptake of REEs by the SILP was evident from the high values of bed volume (BV) at the breakthrough and exhaustive points (Table S3†). In the case of the sulfate feed, the uptake affinity order at a space velocity $\mathrm{SV}=2.7 \mathrm{~h}^{-1}$ was: $\mathrm{Sc}(\mathrm{III})<\mathrm{Fe}(\mathrm{III})<\mathrm{Ca}(\mathrm{II})<\mathrm{Dy}(\mathrm{III})<\mathrm{Al}(\mathrm{III})<\mathrm{Y}$ (III) $<$ $\mathrm{Nd}(\mathrm{III})$. As elucidated from the batch adsorption experiments 

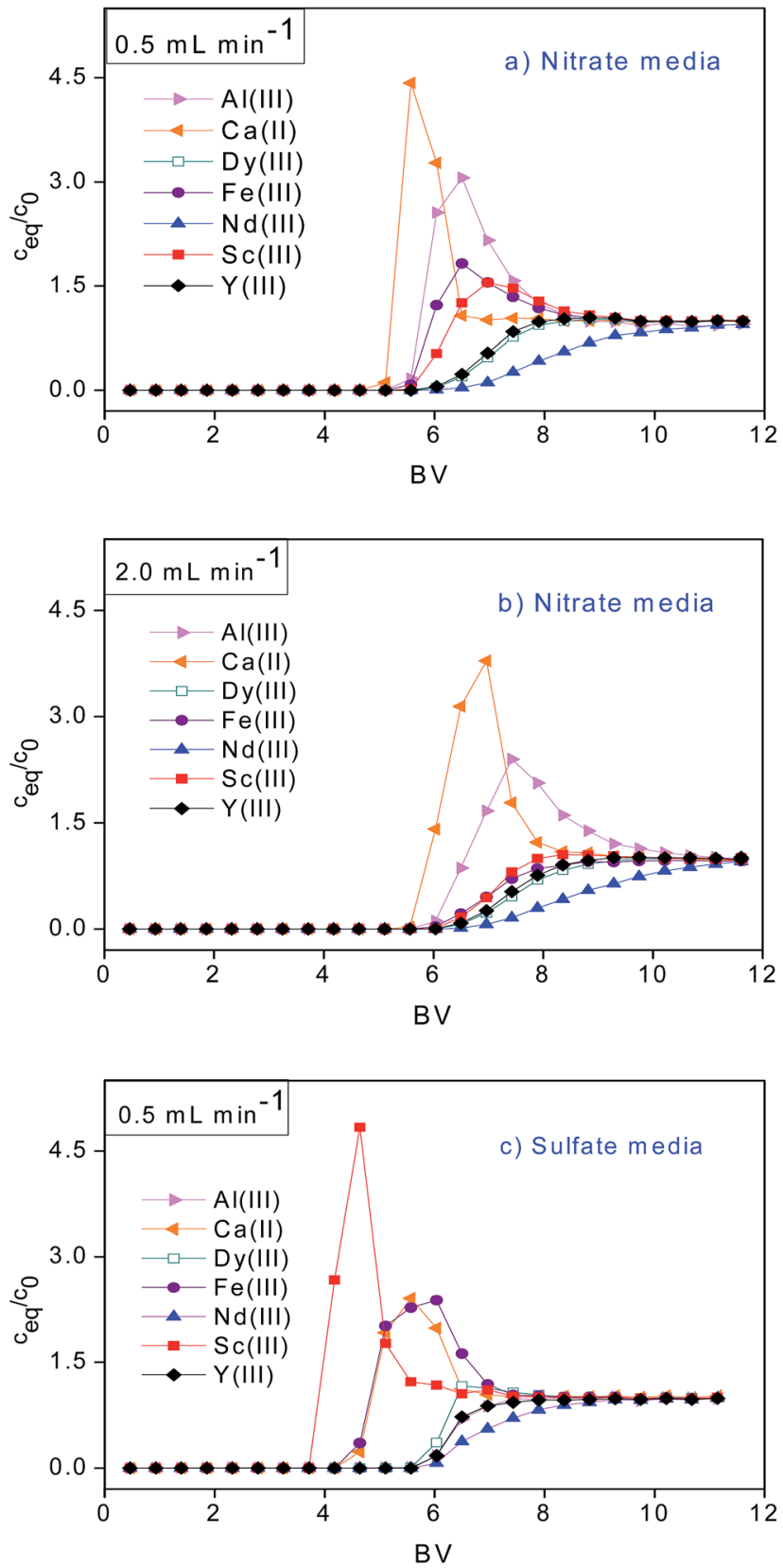

Fig. 3 Breakthrough curves as a function of bed volume (BV) from (a) nitrate media at $0.5 \mathrm{~mL} \mathrm{~min}^{-1}$, (b) nitrate media at $2.0 \mathrm{~mL} \mathrm{~min}^{-1}$ and (c)

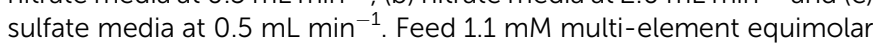
solution. $\mathrm{pH}_{\text {ini }}=1.5$. $\mathrm{pH}_{\text {eq }}$ ranges from 1.2 to 1.5 .

(Fig. 2), the SILP exhibited low affinity for Sc(III) in the sulfate media and high affinity for the other REEs. The uptake affinity order from the nitrate feed at $\mathrm{SV}=2.7 \mathrm{~h}^{-1}$ was favorable for all REEs compared to the base metals: $\mathrm{Ca}$ (II) $<\mathrm{Al}$ (III) $\approx \mathrm{Fe}$ (III) $<\mathrm{Sc}$ (III) $<\mathrm{Y}(\mathrm{III}) \approx \mathrm{Dy}(\mathrm{III})<\mathrm{Nd}(\mathrm{III})$. The SILP was then tested at $\mathrm{SV}=10.8$ $\mathrm{h}^{-1}$ (flow rate of $2.0 \mathrm{~mL} \mathrm{~min}^{-1}$ ) to simulate a SV value within the typical range used for commercial adsorbents applied in metal recovery (between 5 and $40 \mathrm{~h}^{-1}$ ). ${ }^{25}$ The breakthrough points (BV $=6.04$ ) were equal for $\mathrm{Fe}(\mathrm{III}), \mathrm{Sc}(\mathrm{III}), \mathrm{Y}(\mathrm{III})$ and Dy(III). The BVs at the exhaustive points followed a similar order as at $\mathrm{SV}=2.7 \mathrm{~h}^{-1}$ : $\mathrm{Ca}$ (II) $<\mathrm{Al}$ (III) $<\mathrm{Sc}$ (III) $<$ Fe(III) $<$ Y(III) $<$ Dy(III) $<$ Nd(III). A higher BV

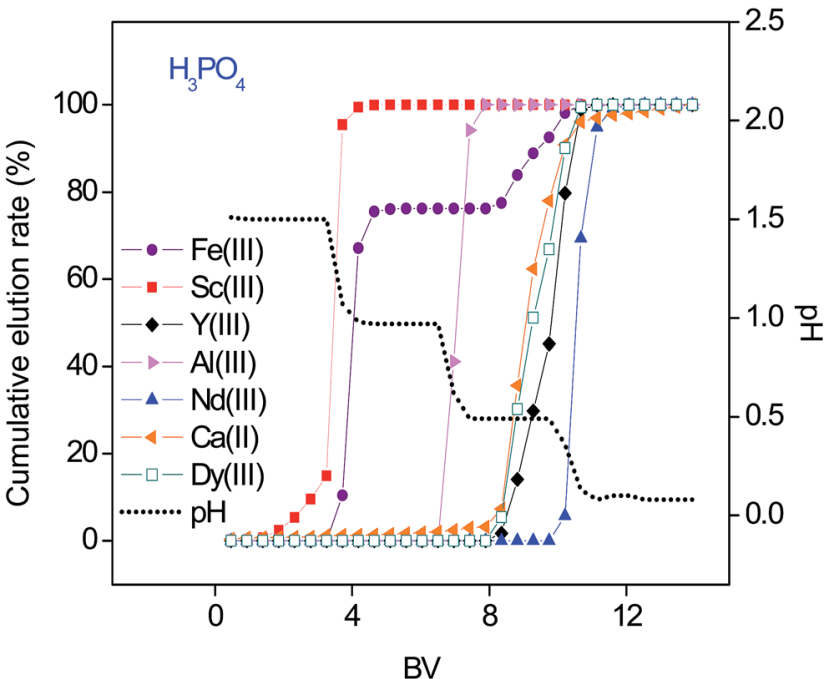

Fig. 4 pH gradient elution with $\mathrm{H}_{3} \mathrm{PO}_{4}$ as a function of the bed volume (BV). Feed $10.0 \mathrm{~mL} 1.1 \mathrm{mM}$ multi-element equimolar solution in nitrate

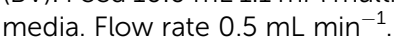

at the exhaustive point for $\mathrm{Fe}(\mathrm{III})$ over the $\mathrm{BV}$ for $\mathrm{Sc}(\mathrm{III})$ at $\mathrm{SV}=$ $10.8 \mathrm{~h}^{-1}$ indicates that the kinetics of the $\mathrm{Fe}(\mathrm{III})$ adsorption are faster.

Adsorption capacities at the breakthrough $\left(q_{0.05}\right)$ and exhaustive point $(q)$ were investigated under acidic conditions $(\mathrm{pH}=1.5)$. The average $q_{0.05}$ value of $0.345 \mathrm{mmol} \mathrm{g}^{-1}$ calculated from the three breakthrough curves (Table S3†) $(\mathrm{RSD}=10.4 \%)$, and the average $q$ value of $0.409 \mathrm{mmol} \mathrm{g}^{-1}(\mathrm{RSD}=15.8 \%)$ are comparable with adsorption capacities of cation-exchange resins and adsorbents used for REEs recovery. ${ }^{16,31}$ The adsorption capacity at $\mathrm{SV}=10.8 \mathrm{~h}^{-1}$ did not significantly differ from the adsorption capacity at $\mathrm{SV}=2.7 \mathrm{~h}^{-1}$. The fast adsorption kinetics indicated practical applicability of the SILP.

The vast majority of adsorbents reported in the literature show higher affinity towards heavy REEs. ${ }^{6,31-33}$ With the SILP, $\mathrm{Nd}$ (III) adsorption resulted in the highest $\mathrm{BV}$ at breakthrough and exhaustive point and the lowest $q_{0.05} / q$ ratio under all investigated conditions (Table S3†) revealing the applicability of the SILP for the recovery and separation of light REEs. It may be assumed that the high preferential uptake of $\mathrm{Nd}(\mathrm{III})$ was enabled by high electrostatic interactions between the $\mathrm{Nd}(\mathrm{III})$ ion and the carboxylic group on the SILP. Additionally, the uptake might be enhanced by the lower hydration enthalpy of $\mathrm{Nd}(\mathrm{III})$ compared to those of other tested trivalent ions. ${ }^{29}$

In the present work the use of complexing agents or volatile solvents was not required for the uptake and selectivity of REEs adsorption, contrary to the previously reported processes..$^{34,35}$ Therefore, the SILP gives the opportunity to efficiently recover all REEs from acidic nitrate BR leachates in the presence of $\mathrm{Ca}(\mathrm{II}), \mathrm{Al}(\mathrm{III})$ and $\mathrm{Fe}(\mathrm{III})$.

\section{Elution curves by the SILP in a fixed bed column.}

Higher binding constants for REEs than that for base elements in nitrate media were evident from the breakthrough curves (Fig. 3, Table S3†). However, in order to obtain purified fractions 


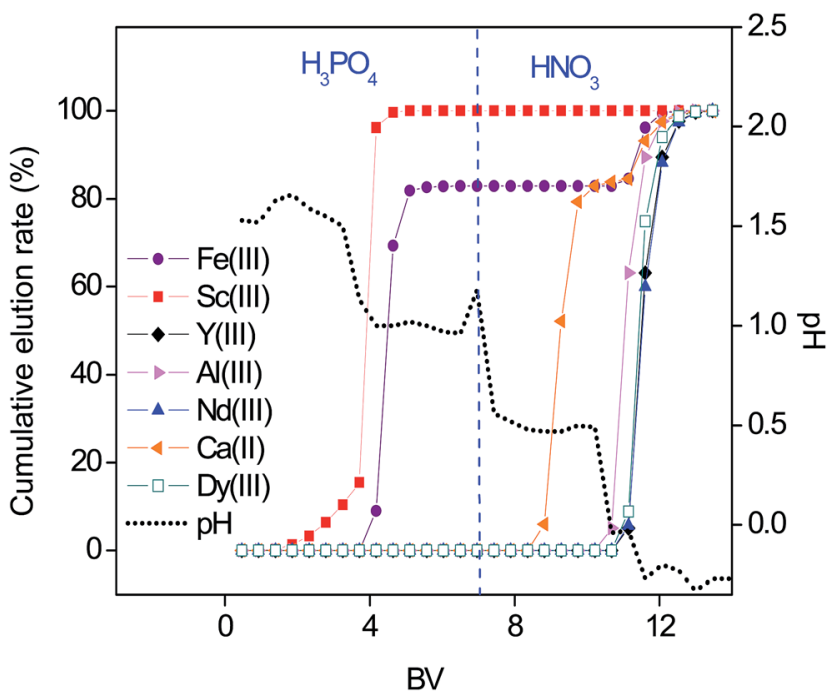

Fig. $5 \mathrm{pH}$ gradient elution with $\mathrm{H}_{3} \mathrm{PO}_{4}$ and $\mathrm{HNO}_{3}$ as a function of the bed volume (BV). Feed $10.0 \mathrm{~mL}$ of $1.1 \mathrm{mM}$ multi-element equimolar

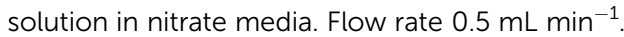

of REEs by a column chromatography, optimization of a selective elution had to be considered. Several attempts were made to separate the REEs from the base elements by the SILP and purities of the REEs in the respective fractions are summarized in the Tables S4-S6.†

First, the separation was tested with a $\mathrm{pH}$ gradient elution with $\mathrm{H}_{3} \mathrm{PO}_{4}$ (Fig. 4). The resulting elution sequence was: $\mathrm{Sc}(\mathrm{III})>$ $\mathrm{Fe}(\mathrm{III})>\mathrm{Al}(\mathrm{III})>\mathrm{Ca}(\mathrm{II}) \approx \mathrm{Dy}(\mathrm{III}) \approx \mathrm{Y}(\mathrm{III})>\mathrm{Nd}(\mathrm{III})$. Despite their similar properties and challenging separation, $\mathrm{Sc}(\mathrm{III})$ was well separated from $\mathrm{Fe}(\mathrm{III})$ and moreover completely separated from $\mathrm{Al}(\mathrm{III}), \mathrm{Ca}(\mathrm{II})$ and other REEs. Nearly complete separation of $\mathrm{Fe}(\mathrm{III})$ and $\mathrm{Al}(\mathrm{III})$ from the other REEs was possible by a $\mathrm{pH}$ gradient elution. However, $\mathrm{Ca}(\mathrm{II})$ was eluted together with the remaining REEs when applying only $\mathrm{H}_{3} \mathrm{PO}_{4}$ for elution. A second elution was then performed with $\mathrm{H}_{3} \mathrm{PO}_{4}$ and $\mathrm{HNO}_{3}$ (Fig. 5). The elution sequence was very similar to the previous one: $\mathrm{Sc}$ (III) $>\mathrm{Fe}($ III $)>\mathrm{Ca}$ (II) $>\mathrm{Al}$ (III) $\approx \mathrm{Dy}$ (III) $\approx \mathrm{Y}$ (III) $\approx \mathrm{Nd}$ (III) . $\mathrm{Sc}$ (III) and $\mathrm{Fe}$ (III) were separated with $\mathrm{H}_{3} \mathrm{PO}_{4}$. $\mathrm{Ca}$ (II) was well separated from the other tested elements with $\mathrm{HNO}_{3}(\mathrm{pH}=0.5)$. However, with $\mathrm{HNO}_{3}(\mathrm{pH} \leq 0.0), \mathrm{Al}(\mathrm{III})$ was co-eluted with the remaining REEs.

Therefore a third three-step elution profile comprising $\mathrm{H}_{3} \mathrm{PO}_{4}$ and $\mathrm{HNO}_{3}$ was applied (Fig. 6a). First, Sc(III) and Fe(III) were eluted with $\mathrm{H}_{3} \mathrm{PO}_{4}$ (pH between 1.5 and 1.0). Then $\mathrm{Ca}$ (II) was eluted with $\mathrm{HNO}_{3}(\mathrm{pH}=0.5)$. Lastly, $\mathrm{Al}(\mathrm{III})$ was removed by further decreasing $\mathrm{pH}$ gradient with $\mathrm{H}_{3} \mathrm{PO}_{4}(\mathrm{pH}$ from 0.5 to 0.1 ) resulting in a good separation from Dy(III), Y(III) and $\mathrm{Nd}(\mathrm{III})$. Moreover, when the REEs were eluted with $\mathrm{H}_{3} \mathrm{PO}_{4}, \mathrm{Nd}(\mathrm{III}) / \mathrm{Dy}(\mathrm{III})$ and $\mathrm{Nd}(\mathrm{III}) / \mathrm{Y}(\mathrm{III})$ molar ratios were much higher than when eluting with $\mathrm{HNO}_{3}$ (Table 1), indicating their better separation with $\mathrm{H}_{3} \mathrm{PO}_{4}$. Using the same optimal elution profile, but a higher flow rate $\left(2.0 \mathrm{~mL} \mathrm{~min}^{-1}\right)$ (Fig. $\left.6 \mathrm{~b}\right)$, the molar ratios and therefore the separation between light and heavy REEs decreased (Table 1). Moreover, with the higher elution flow rate $\mathrm{Sc}(\mathrm{IIII} / \mathrm{Fe}(\mathrm{III})$ molar ratio and their separation also decreased
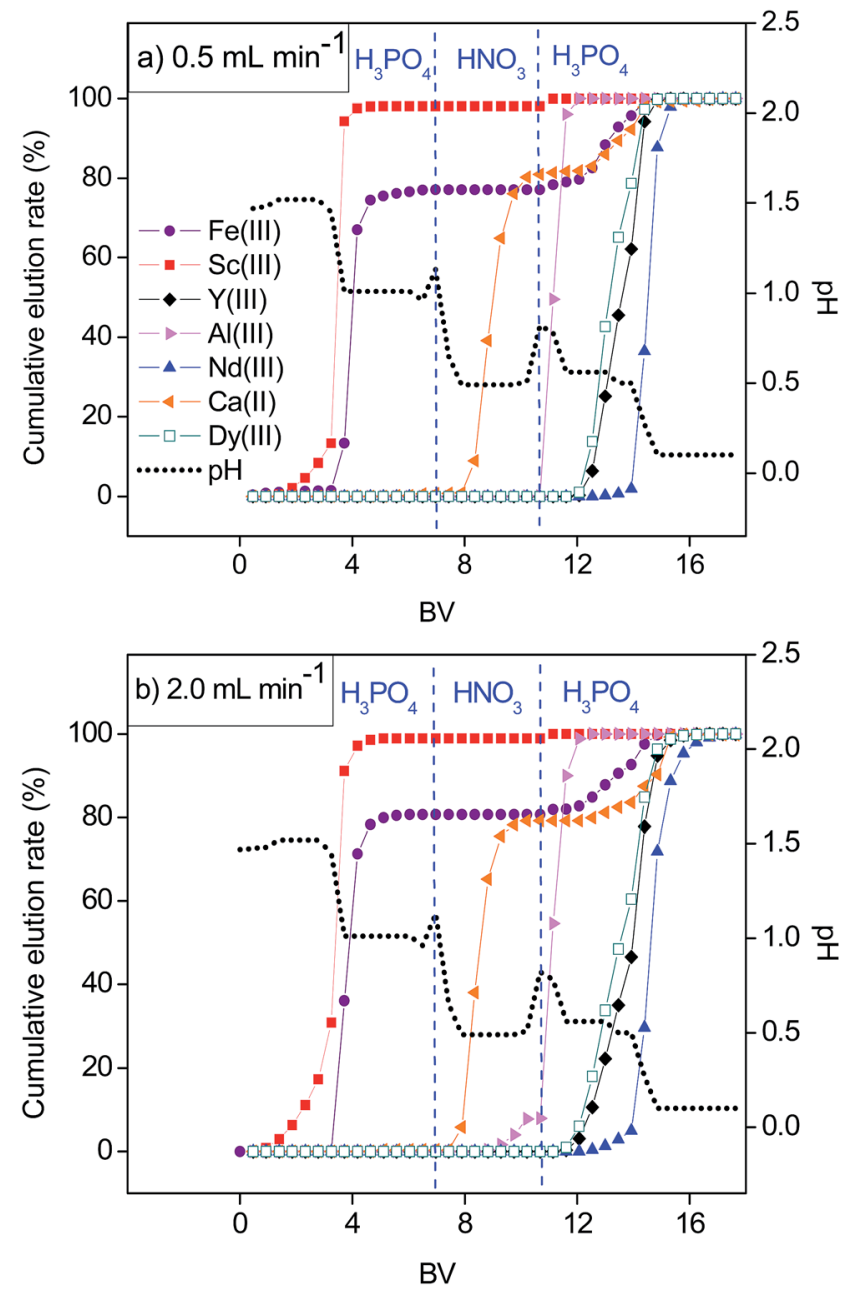

Fig. 6 Optimized $\mathrm{pH}$ gradient elution with $\mathrm{H}_{3} \mathrm{PO}_{4}$ and $\mathrm{HNO}_{3}$ as a function of the bed volume (BV). Feed $10.0 \mathrm{~mL}$ of $1.1 \mathrm{mM}$ multielement equimolar solution in nitrate media. Flow rate (a) $0.5 \mathrm{~mL} \mathrm{~min}^{-1}$

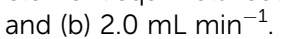

(Fig. 6 and 7). The contact time between eluent and the adsorbent was not sufficient for the effective elution and separation of ions with similar physico-chemical properties.

Optimal elution with $\mathrm{H}_{3} \mathrm{PO}_{4}$ and $\mathrm{HNO}_{3}$ was tested as well with the sulfate media (Fig. 8). The elution trend remained the same as with the nitrate media: $\mathrm{Sc}$ (III) $>\mathrm{Fe}$ (III) $>\mathrm{Ca}$ (II) $>\mathrm{Al}$ (III) $>$ $\mathrm{Dy}(\mathrm{III}) \approx \mathrm{Y}(\mathrm{III})>\mathrm{Nd}(\mathrm{III})$. With the sulfate media, $\mathrm{Sc}(\mathrm{III}) / \mathrm{Fe}(\mathrm{III})$ and $\mathrm{Nd}(\mathrm{III}) /$ REEs molar ratios exceeded the values found when using the nitrate media (Fig. 7, Table 1). The total amount of all

Table 1 Comparison of $\mathrm{Nd}(\mathrm{II}) / \mathrm{Dy}(\mathrm{III})$ and $\mathrm{Nd}(\mathrm{\prime II}) / \mathrm{Y}(\mathrm{II})$ molar ratios in fractions after elution with $\mathrm{H}_{3} \mathrm{PO}_{4}$ and $\mathrm{HNO}_{3}$. Feed $10.0 \mathrm{~mL}$ of $1.1 \mathrm{mM}$ multi-element equimolar solutions. $\mathrm{pH}_{\text {ini }}=1.5$

\begin{tabular}{lllll}
\hline Eluent & $\mathrm{HNO}_{3}$ & $\mathrm{H}_{3} \mathrm{PO}_{4}$ & $\mathrm{H}_{3} \mathrm{PO}_{4}$ & $\mathrm{H}_{3} \mathrm{PO}_{4}$ \\
Media & Nitrate & Sulfate & Nitrate & Nitrate \\
Flow rate, $\mathrm{mL} \mathrm{min}^{-1}$ & 0.5 & 0.5 & 0.5 & 2.0 \\
BV & $11.6-12.5$ & $14.9-17.2$ & 14.9 & 14.9 \\
No. of fractions & 3 & 6 & 1 & 1 \\
Nd/Dy & 0.96 & 26.8 & 18.2 & 3.80 \\
Nd/Y & 0.76 & 13.9 & 7.85 & 2.06
\end{tabular}




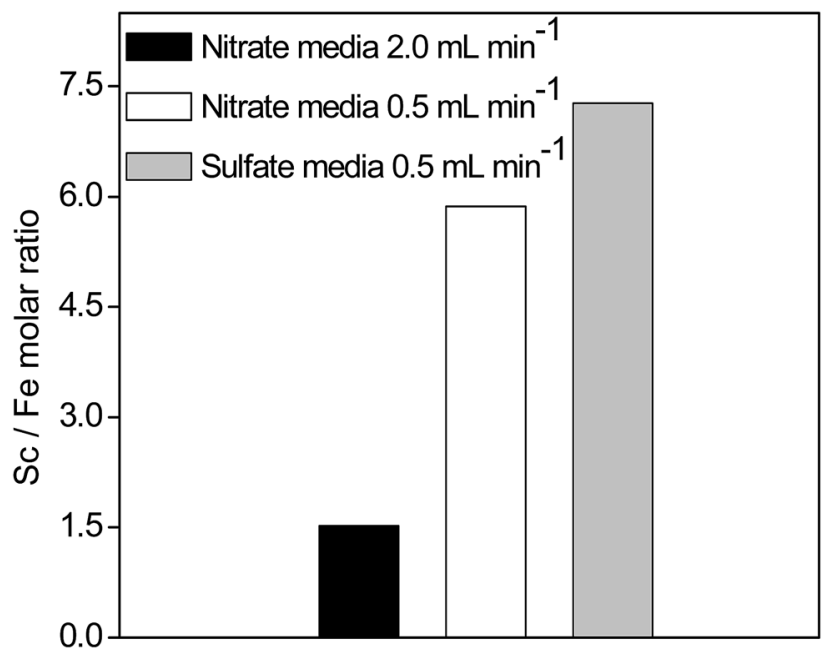

Fig. 7 Comparison of Sc(III)/Fe(III) molar ratios after chromatography separation from $10.0 \mathrm{~mL}$ of $1.1 \mathrm{mM}$ multi-element equimolar solutions. Eluent $0.12 \mathrm{~mol} \mathrm{~L}^{-1} \mathrm{H}_{3} \mathrm{PO}_{4}(\mathrm{pH}=1.5)$. $\mathrm{BV}=3.7 \mathrm{~mL}$, single fraction of $5.0 \mathrm{~mL}$. $\mathrm{pH}_{\text {ini }}=1.5$.

elements $(n \approx 0.0077 \mathrm{mmol})$ in the sulfate feed was much lower than the $q$ of the SILP $\left(0.409 \mathrm{mmol} \mathrm{g}^{-1}\right)$. Therefore, the Sc(III) uptake rate was not diminished by the presence of other elements. The lower Sc(III) binding constant from equimolar sulfate feed and consequently lower retention time on the column, improved the $\mathrm{Sc}(\mathrm{III} / \mathrm{Fe}$ (III) separation. In a similar manner, Y(III) and Dy(III) migrated through the SILP faster than $\mathrm{Nd}(\mathrm{III})$ due to stronger electrostatic interactions of the smaller ions of Y(III) and Dy(III) with the sulfate ligand.

A promising separation between the REEs and base elements from the synthetic feeds was accomplished by an optimized elution with $\mathrm{H}_{3} \mathrm{PO}_{4}$ and $\mathrm{HNO}_{3}$. However, in real BR leachates, the concentrations of the accompanying elements are much

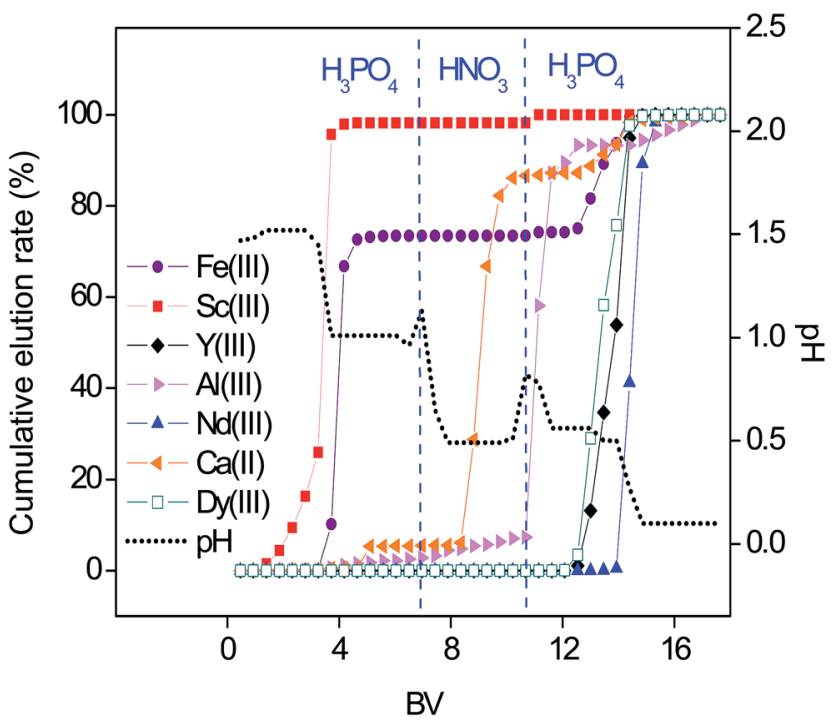

Fig. 8 Optimized $\mathrm{pH}$ gradient elution with $\mathrm{H}_{3} \mathrm{PO}_{4}$ and $\mathrm{HNO}_{3}$ as a function of the bed volume (BV). Feed $10.0 \mathrm{~mL}$ of $1.1 \mathrm{mM}$ multielement equimolar solution in sulfate media. Flow rate $0.5 \mathrm{~mL} \mathrm{~min}{ }^{-1}$. higher than those of the REEs. Therefore, a real nitrate leachate was tested (Fig. 9) and its initial composition and the recovery of elements (regarded as the \% of the amount of metal ions loaded on the SILP compared to the amount of metal ions present in the feed) are summarized in the Table 2.

Trace amounts of $\mathrm{Sc}(\mathrm{III}$ ) and $\mathrm{Y}$ (III) (up to $3.7 \mathrm{ppm}$ ) were effectively recovered by the SILP even in the presence of accompanying elements in concentrations up to $4.9 \mathrm{~g} \mathrm{~L}^{-1}$. Despite the high affinity of the SILP towards Nd(III), about $29 \%$ of $\mathrm{Nd}(\mathrm{III})$ was lost during the washing step between the sample and the eluting agent. The extremely complex matrix of the leachate gave rise to diminished $\mathrm{Nd}$ (III) uptake. Besides a wide range of base and minor elements, BR comprises a variety of organic compounds derived from bauxite and/or the Bayer process, which can be also present in the leachate. ${ }^{10}$ Although Dy(III) could not be detected in the initial feed composition due to the matrix effects, it was collected in the fractions which were purified from the majority of the compounds initially present. Most of $\mathrm{Si}(\mathrm{Iv})$ and $\mathrm{Ti}(\mathrm{Iv})$ were already removed from the column in the washing step, resulting in a recovery by the SILP of $4.7 \%$ and $18.3 \%$, respectively. Probably, the remaining amounts could have been removed by a prolonged washing step between the sample loading and elution. The elution sequence with the real BR leachate was in agreement with the optimized elution sequence tested with the synthetic feed: $\mathrm{Si}(\mathrm{IV}) \approx \mathrm{Sc}(\mathrm{III})>\mathrm{Fe}(\mathrm{III}) \approx$ $\mathrm{Ti}(\mathrm{Iv})>\mathrm{Ca}(\mathrm{II})>\mathrm{Al}(\mathrm{III})>\mathrm{Dy}(\mathrm{III}) \approx \mathrm{Y}(\mathrm{III})>\mathrm{Nd}(\mathrm{III})$. Highly concentrated $\mathrm{Ca}(\mathrm{II})$ and $\mathrm{Al}(\mathrm{III})$ ions migrated faster through the column. Elution of $\mathrm{Ca}(\mathrm{II})$ and $\mathrm{Al}(\mathrm{III})$ started at eluent $\mathrm{pH}$ of 1.5 and 1.0, respectively. $\mathrm{Ca}$ (II) elution was enhanced with $\mathrm{HNO}_{3}(\mathrm{pH}=0.5)$. Compared to the feed, the REEs in the resulting fractions were significantly purified from the major elements in BR (Fig. 10) and the recovered amounts of REEs from the BR leachate and $w t \%$ of impurities in REEs fractions are summarized in the Table S7. $\dagger$ Equilibrium versus initial molar ratio of $\mathrm{Nd}(\mathrm{III})$ towards $\mathrm{Ca}(\mathrm{II}), \mathrm{Fe}(\mathrm{III}), \mathrm{Al}(\mathrm{III})$ reached values up to 37,300 and 660, respectively.

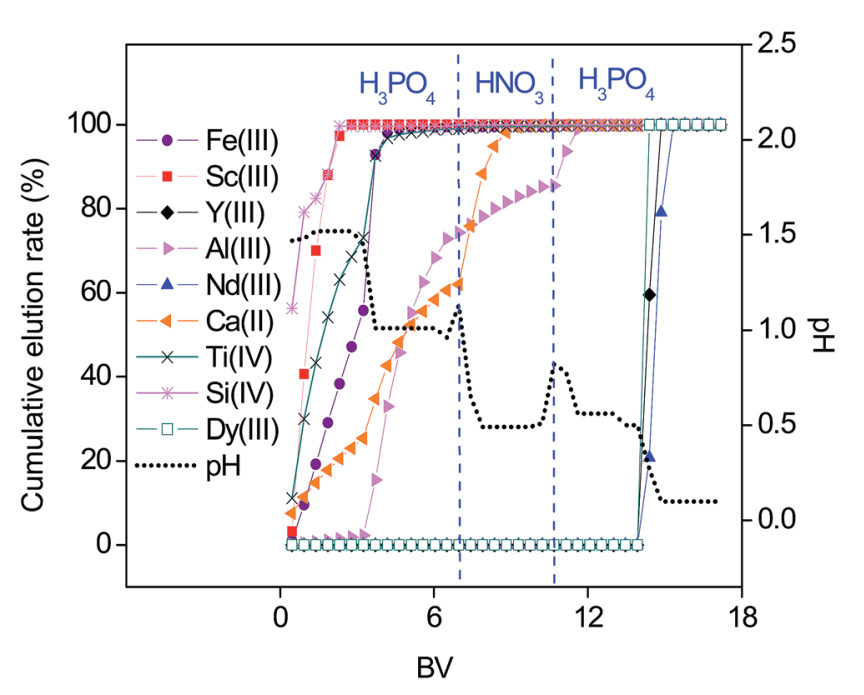

Fig. 9 Gradient $\mathrm{pH}$ elution with $\mathrm{H}_{3} \mathrm{PO}_{4}$ and $\mathrm{HNO}_{3}$ as a function of the bed volume (BV). Feed $2.0 \mathrm{~mL}$ of BR leachate with $0.7 \mathrm{~N} \mathrm{HNO}_{3} . \mathrm{pH}_{\text {ini }}=$

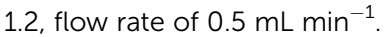


Table 2 Composition of BR leachate and recovery (\%) of elements by the SILP ${ }^{a}$

\begin{tabular}{lllllllll}
\hline & $\mathrm{Al}$ & $\mathrm{Ca}$ & $\mathrm{Si}$ & $\mathrm{Ti}$ & $\mathrm{Fe}$ & $\mathrm{Nd}$ & $\mathrm{Sc}$ & $\mathrm{Y}$ \\
\hline Initial concentration $\left(\mathrm{mg} \mathrm{L}^{-1}\right)$ & 2454 & 4929 & 2031 & 822 & 611 & 7.1 & 3.7 & 3.2 \\
Recovery (\%) & 97.9 & 70.9 & 4.7 & 18.3 & 99.1 & 71.8 & 100 & 100 \\
$*$
\end{tabular}

$a *$ The Dy concentration in the leachate was below the detection limit of ICP-OES in the presence of very high concentrations of other elements, which is not unexpected, since the Dy content in BR is very low. ${ }^{12}$ However, Dy could be quantified in the fractions purified from the major elements.
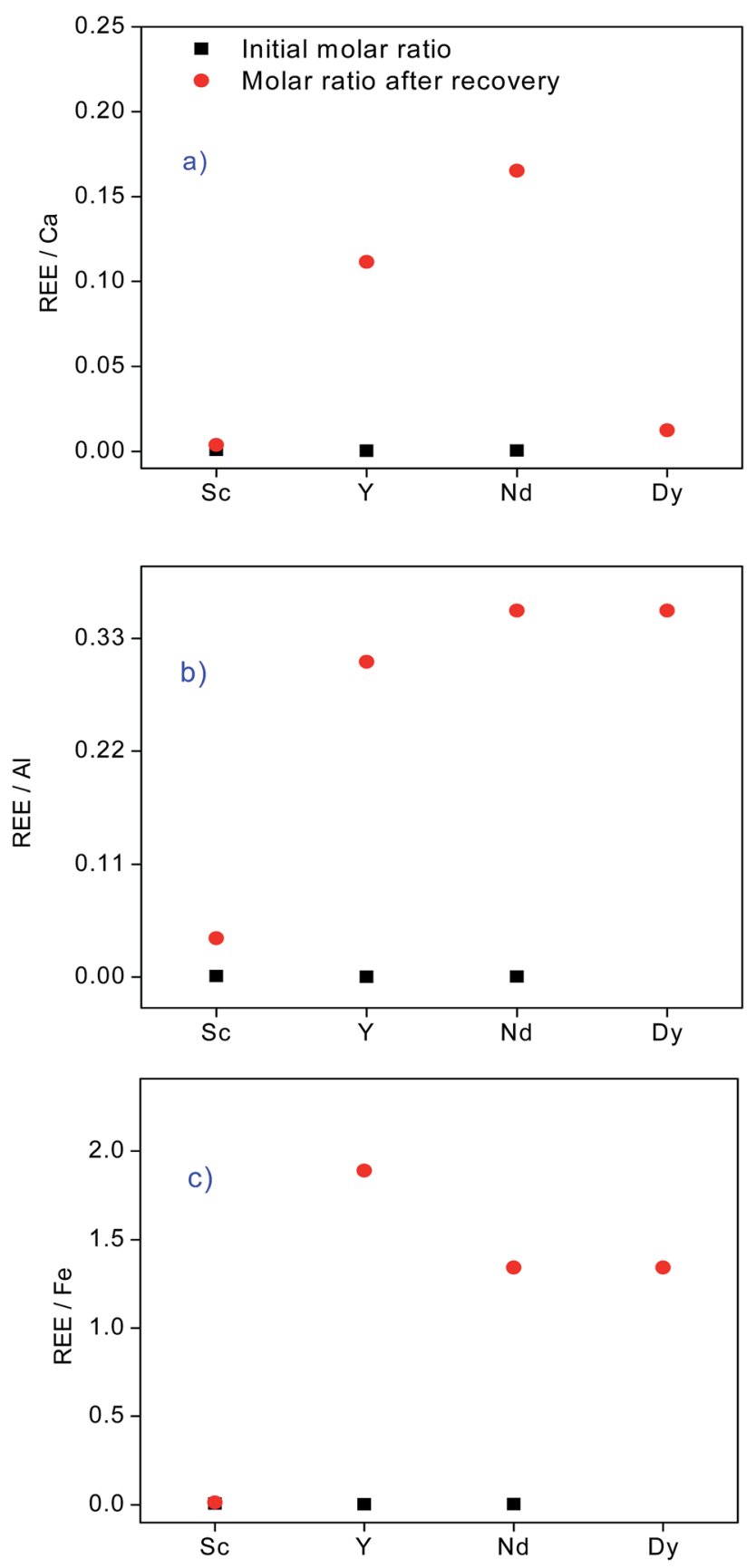

Fig. 10 Molar ratios between REEs and (a) $\mathrm{Ca}$, (b) $\mathrm{Al}$, and (c) Fe, in the real BR leachate before the recovery by the SILP $(\mathbf{\square})$ and in the fractions collected after optimized elution with $\mathrm{H}_{3} \mathrm{PO}_{4}$ and $\mathrm{HNO}_{3}(\bullet)$.
In a previous study of $\mathrm{Sc}(\mathrm{III})$ recovery from the $\mathrm{BR}, \mathrm{Na}_{2} \mathrm{SO}_{3}$ was used for on-column $\mathrm{Fe}(\mathrm{III})\left(100 \mathrm{ppm}\right.$ ) reduction to $\mathrm{Fe}(\mathrm{II}){ }^{36}$ Moreover, Sc(III) recovery was achieved only after a number of collected fractions (e.g. up to $115 \mathrm{BV}) .{ }^{\mathbf{1 6 , 3 6}}$ In those studies other REEs were not considered for recovery and purification. Furthermore, when a commercial cation-exchange resin was used for the recovery of REEs from BR, 4-24\% of Y(III) was coeluted with $\mathrm{Sc}(\mathrm{III}) .{ }^{37}$ In the present study with the SILP, Sc(III) was effectively recovered and especially separated from other REEs in only several initial fractions (up to 11 fractions, 5.1 BV). $\mathrm{Sc}(\mathrm{III}) / \mathrm{Fe}(\mathrm{III})$ separation can be further enhanced by depleting Fe(III) concentration (611 ppm) in the leachate. ${ }^{\mathbf{1 4}}$ A good separation of $\mathrm{Nd}$ (III), Y(III) and Dy(III) from other elements was achieved (Fig. 8 and 9, Table 1). The SILP was reused in all conducted experiments (at least 9 times), confirming its high reusability.

The high separation and recovery of elements opens the way to the BR valorization. Note that even better results can probably be achieved as the tested BR leachate was obtained after a non-optimized leaching process. In the present study, the possibility for REEs recovery and separation by the novel SILP from a secondary resource such as BR was explored on a laboratory scale. The results with the leachate were used for a proofof-concept. The chromatography process with the SILP can be further designed to exploit its maximum performance in terms of REEs separation and purification. ${ }^{38}$ The developed separation procedure could be utilized in diverse applications, e.g. the recovery of $\mathrm{Nd}$ from spent $\mathrm{NdFeB}$ magnets or the separation of light from the rest of REE (with higher risk of under-supply), the latter being a key pre-processing step in the production of REEs.

\section{Conclusion}

The SILP [Hbet-STFSI-PS-DVB] was evaluated for the REEs uptake from acidic nitrate and sulfate media. Breakthrough curve experiments revealed generally preferential uptake of REEs (Sc, Y, Nd, Dy) over the base elements (Ca, Al, Fe) in BR, except in the case of $\mathrm{Sc}$ (III) from sulfate media due to its interactions with the sulfate ligands. Fast adsorption kinetics indicated a potential applicability of the SILP for a large-scale process. The separation of REEs into three groups (Sc, light REEs and heavy REEs) was achieved by an optimized 3-step $\mathrm{pH}$ gradient elution with $\mathrm{H}_{3} \mathrm{PO}_{4}$ and $\mathrm{HNO}_{3}$. The elution followed the sequence: $\mathrm{Sc}$ (III) $>\mathrm{Fe}$ (III) $>\mathrm{Ca}$ (II) $>\mathrm{Al}$ (III) $>\mathrm{Dy}$ (III) $\approx \mathrm{Y}$ (III) $>$ Nd(III). The REEs were enriched and purified from the base elements from the real BR leachate. The recovery and purification results are even more valuable when considering the fact 
that there was no optimization of the leaching process, neither pretreatments to remove interfering major elements, nor chelating agents to adsorb only the elements of interest. Furthermore, the SILP showed high reusability and stability without decreasing the recovery efficiencies. This novel chromatographic method is promising for efficient separation and purification of REEs.

\section{Conflicts of interest}

There are no conflicts to declare.

\section{Acknowledgements}

The research leading to these results has received funding from the European Community's Horizon 2020 Programme under Grant Agreement number 636876 (REDMUD - H2020-MSCAITN-2014). Project website: etn.redmud.org.

\section{References}

1 V. Fernandez, Resour. Policy, 2017, 53, 26-45.

2 K. Binnemans, P. T. Jones, B. Blanpain, T. van Gerven and Y. Pontikes, J. Cleaner Prod., 2015, 99, 17-38.

3 European Commission, Report on the critical raw materials for the EU, 2017, pp. 1-8.

4 Z. Liu, Y. Zong, H. Li, D. Jia and Z. Zhao, J. Rare Earths, 2017, 35, 896-905.

5 P. Smith, Hydrometallurgy, 2009, 98, 162-176.

6 Z. H. Wang, G. X. Ma, J. Lu, W. P. Liao and D. Q. Li, Hydrometallurgy, 2002, 66, 95-99.

7 S. Liu, X. Guan, S. Zhang, C. Xu, H. Li and J. Zhang, Mater. Lett., 2017, 191, 222-224.

8 S. Rai, D. H. Lataye, M. J. Chaddha, R. S. Mishra, P. Mahendiran, J. Mukhopadhyay, C. K. Yoo and K. L. Wasewar, Adv. Mater. Sci. Eng., 2013, 2013, 1-7.

9 K. Evans, J. Sustain. Metall., 2016, 2, 316-331.

$10 \mathrm{~K}$. Evans, Proceedings of the Bauxite residue valorisation and best practices conference, Leuven, Belgium, 5-8 October 2015, p. 113.

11 S. P. Yatsenko and I. N. Pyagai, Theor. Found. Chem. Eng., 2010, 44, 563-568.

12 C. R. Borra, Y. Pontikes, K. Binnemans and T. Van Gerven, Miner. Eng., 2015, 76, 20-27.

13 Y. C. Y. Gao, J. Rare Earths, 2010, 28, 622-626.

14 M. Ochsenkuhn-Petropulu, Th. Lyberopulu, T. Ochsenkuhn and G. Parissakis, Anal. Chim. Acta, 1996, 319, 249-254.

15 M. Th. Ochsenkühn-Petropoulou, K. S. Hatzilyberis, L. N. Mendrinos and C. E. Salmas, Ind. Eng. Chem. Res., 2002, 41, 5794-5801.
16 C. R. Borra, B. Blanpain, Y. Pontikes, K. Binnemans and T. Van Gerven, J. Sustain. Metall., 2017, 3, 393-404.

17 R. M. Rivera, G. Ounoughene, C. R. Borra, K. Binnemans and T. van Gerven, Miner. Eng., 2017, 112, 92-102.

18 J. Roosen, S. van Roosendael, C. R. Borra, T. van Gerven, S. Mullens and K. Binnemans, Green Chem., 2016, 18, 2005-2013.

19 A. Akcil, N. Akhmadiyeva, R. Abdulvaliyev, Abhilash and P. M. Meshram, Miner. Process. Extr. Metall. Rev., 2017, 4, 1-7.

20 S. Reid, J. Tam, M. Yang and G. Azimi, Sci. Rep., 2017, 7, 15252.

21 P. E. Tsakiridis, S. Agatzini-Leonardou and P. Oustadakis, J. Hazard. Mater., 2004, 116, 103-110.

22 B. Onghena, C. R. Borra, T. van Gerven and K. Binnemans, Sep. Purif. Technol., 2017, 176, 208-219.

23 D. Avdibegović, M. Regadío and K. Binnemans, RSC Adv., 2017, 7, 49664-49674.

24 J.-G. Li, T. Ikegami and T. Mori, J. Mater. Res., 2003, 18, 18161822.

25 T. Ogata, H. Narita and M. Tanaka, Hydrometallurgy, 2015, 155, 105-109.

26 P. Davris, E. Balomenos, D. Panias and I. Paspaliaris, Hydrometallurgy, 2016, 164, 125-135.

27 J. Zhang, B. Zhao and B. Schreiner, Separation Hydrometallurgy of Rare Earth Elements, Springer International Publishing AG, Switzerland, 2016.

28 S. Cotton, Lanthanide and Actinide Chemistry, John Wiley \& Sons, Ltd, Chichester, UK, 2006.

29 D. W. Smith, J. Chem. Educ., 1977, 9, 540-542.

30 S. Schrödle, W. Wachter, R. Buchner and G. Hefter, Inorg. Chem., 2008, 47, 8619-8628.

31 Y. Takahashi, K. Kondo, A. Miyaji, Y. Watanabe, Q. Fan, T. Honma and K. Tanaka, PLoS One, 2014, 9, e114858.

32 T. Ogata, H. Narita, M. Tanaka, M. Hoshino, Y. Kon and Y. Watanabe, Sep. Purif. Technol., 2016, 159, 157-160.

33 B. Nagaphani Kumar, S. Radhika and B. Ramachandra Reddy, Chem. Eng. J., 2010, 160, 138-144.

34 H. Hubicka and D. Kołodyńska, Hydrometallurgy, 2004, 71, 343-350.

35 J. P. Faris and J. W. Warton, Anal. Chem., 1962, 34, 10771080.

36 W. Zhang, R. Koivula, E. Wiikinkoski, J. Xu, S. Hietala, J. Lehto and R. Harjula, ACS Sustainable Chem. Eng., 2017, 5, 3103-3114.

37 L.-A. Tsakanika and M. Ochsenkuehn-Petropoulou, Proceedings of the Bauxite residue valorisation and best practices conference, Leuven, Belgium, 5-8 October 2015, pp. 309-315.

38 T. S. J. Siitonen, Chem. Eng. Sci., 2015, 122, 436-451. 